\title{
Gruppebasert prosjektoppgave i matematikk: Veiledernes erfaringer
}

\author{
Thomas Gjesteland ${ }^{* 1}$, Vegard Lima ${ }^{1}$, Sverre Lunøe-Nielsen ${ }^{1}$, Farzad Radmehr ${ }^{1,2}$ and Simon Goodchild ${ }^{1}$ \\ ${ }^{1}$ Department of Engineering Sciences, Universitetet i Agder, Norway \\ ${ }^{2}$ Western Norway University of Applied Sciences, Norway
}

\begin{abstract}
I denne presentasjonen vil vi rapportere veilederes erfaringer med å bidra $\mathbf{i}$ et matematisk modelleringsprosjekt. Prosjektet ble introdusert i begynnelsen av forste semester matematikkurs for ingeniørstudenter. Målet med prosjektet er å knytte matematikken til realistiske ingeniørfag problemstillinger og at studentene skal få en nærmere tilknytning til faglærerne i sitt felt. Vi ønsker også å lære studentene flere matematiske kompetanser, som det er vanskelig å trene i forelesninger og øvingstimer. I prosjektet ble 483 studenter delt i 70 grupper som ble veiledet av 20 faglig ansatte fra alle seksjoner av ingeniøravdelingene. Veilederne rapporterer om at de opplever prosjektoppgaven som et positivt bidrag i matematikkfaget, og at studentene var fornøyde med denne oppgaven. Veilederne rapporterte også at veiledningen var tidkrevende og at gruppedynamikk var en utfordring.
\end{abstract}

\section{INTRODUKSJON}

Filmen Karate Kid [1] fra 1984 handler om Daniel LaRusso som ønsker å lære seg karate. Han ber Mr. Miyagi om å trene ham. Når Daniel kommer til Mr. Miyagi begynner de ikke med karate. De starter med at Daniel må polere biler og male hus og gjerde. Filmen viser en litt skuffet Daniel, som istedenfor å lære karate, lærer seg bevegelsene til å polere bilen mens vi hører Mr. Miyagis ord "Vax on. Vax off". Dette gjør Mr. Miyagi fordi han ønsker at Daniel skal lære seg de grunnleggende bevegelsene som en trenger i karate. Daniel gjennomfører disse oppgavene. Senere viser Mr. Miyagi Daniel karate. Da skjønner Daniel at de oppgavene, som han motvillig gjennomørte, har lært ham de bevegelsene han trenger i karate. I matematikk er det viktig å lære grunnleggende regning, prosedyrer og ideer. Vår erfaring er at flere studenter lærer seg grunnleggende matematikk, slik Daniel LaRusso gjennomførte poleringen og malingen. Senere skjønner disse studentene at dette har sin naturlige plass i ingeniørfagene. Andre studenter er ikke like tålmodige. De mister motet i løpet av denne grunnleggende fasen, før de rekker å innse nytten av disse ferdighetene innenfor ingeniørfagene. Vår hypotese er at ved å innføre en prosjektoppgave, som er tett knytet mot ingeniørfagene, tidlig i det første matematikkemnet vil flere studenter se nytten av matematikken og legge inn den innsatsen som trengs for å lære grunnlegende matematikk. Studier fra andre land (f.eks. [2] ) viser at innføring av problemløsning og modellering i matematikk kan være effektiv for å forbedre studentenes motivasjon, engasjement og ytelse i matematikk. Imidlertid krever utviklingen av slike tilnærminger forelesernes tid og ressurser.

Et formål med prosjektoppgaven er å trene studentene i flere matematiske kompetanser. I det danske KOM-prosjektet [3] definerte Niss og Højgaard åtte matematiske komptansener. De åtte kompetansene er Representasjonskompetanse, Symbol-og formalisme-kompetanse, Kommunikasjonskompetanse,hjelpemiddelkompetanse, resonneringskompetanse, modellerings-kompetanse problembehandlings-kompetans og tankeganskompetanse. I prosjektoppgaven ønsker vi spesielt at studentene skal lære seg å kommunisere matematikk. De er nødt til å lese og forstå oppgaven og de må rapportere resultatene skriftlig. Dette krever også at studentene har symbol- og formalisme -kompetanse og representasjonskompetanse fordi oppgaven er skrevet i et formelt matematisk språk og de må representere en fysisk modell. Det forventes også at studentene bruker et riktig symbol-og formalisme i rapporten. Studentene blir trent i hjelpemiddelkompetanse ved at de er nødt til å bruke programmering til å løse deler av prosjektet og de skal plotte løsninger. De har også mulighet til å bruke Computer algebra system (CAS) eller lignende for å teste utregninger.

\footnotetext{
*thomas.gjesteland@uia.no
} 
Vi ønsker at prosjektoppgaven skal gi studentene er mer konseptuell forståelse av matematikk Et eksempel på god konseptuell forståelse av matematikk ble presentert for våre ingeniørstudenter i 2018 av Jaworski [4]. Her viste Jarworski et eksempel fra aerodynamikken. I en boken, Engineering mathematics through applications [5], er uttrykket for luftmotstanden (drag) til en vinge er gitt ved uttrykket

$$
\frac{C_{D}+k C_{L}^{2}}{C_{L}} .
$$

For hvilken verdi av $C_{L}$ har vingen mist luftmotstand? For mange studenter er denne oppgaven mye vanskeligere enn en oppgave der spørsmålet er finne hvor $f(x)$ har et minimum når

$$
f(x)=\frac{c}{x}+k x .
$$

De studentene som har en god konseptuell forståelse, vil se at disse problemene er like.

Vi ønsker også at prosjektoppgaven skal føre til mestringsfølelse blant studentene. En tidligere studie av førsteårs ingeniørstudenter viste at studentenes følelse av mestringsevne (self-afficacy) er viktig for dybdelæring i matematikk [6].

Denne presentasjonen handler om veilederens perspektiv på den obligatoriske prosjektoppgaven i faget MA 178. Dataene er samlet inn i et evalueringsmøte og gjennom samtale med veilederne. Del 2 gir en gjennomgang av prosjektoppgaven studentene skulle gjennomføre. I del 3 presenteres veiledernes erfaringer og i del 4 presenteres konklusjonene.

\section{OM PROSJEKTOPPGAVEN}

Prosjektet består av to deler. Den første delen handler om nummeriske tilnærminger til den deriverte av reelle funksjoner og undersøke hvordan feilen i de nummeriske uttrykket varierer og begrensingene ved nummerisk derivasjon. I del to skal studentene bruke Newton-Raphsons metode for å finne løsinger av ikke-linære ligninger. Prosjektoppgaven er basert på et ingeniørfaglig problem som er modifisert av faglærerne slik at den passer godt inn i pensumet til faget. Figur 1 viser den ingeniørfaglige delen av prosjektoppgaven. Figuren viser en landbasert oljepumpe (derrick). Derriken består av en roterende arm, $L_{A B}$ som er hengslet sammen med $L_{B C}$ og $L_{C D}$. Punkt $A$ og $D$ er faste punkt. Oppgaven består i å finne vinkel $\theta_{2}$ når vinkel $\theta_{1}$ er kjent. For å klare dette må studentene først skjønne geometrien til systemet og utlede ligningen $f\left(\theta_{2}\right)=0$ basert på lining (7) og (8) i figur 1. Når studentene har funnet utrykket $f\left(\theta_{2}\right)$ kan de bruke Newton-Raphsons metode til å finne vinkel $\theta_{2}$ for gitte verdier av $\theta_{1}$. For å finne uttrykket for $f\left(\theta_{2}\right)=0$ må studentene ha Representasjonskompetanse og Symbol- og formalisme-kompetanse. De må vise at ligning (7) i oppgaven representerer en rettvinklet trekant. De må videre håndtere symbolene i ligning (7) og (8) til å omforme dette til et uttrykk på formen $f\left(\theta_{2}\right)=0$. Videre må studentene bruke derivasjon med hensyn på $\theta_{2}$ for å lage algoritmen som løser ligningen. Ligninen $f\left(\theta_{2}\right)=0$ har to løsninger. Studentene skal utforske den fysiske betydningen av de to forskjellige løsningene.

\section{ERFARINGER FRA VEILEDNINGEN}

I faget MA 178 var det høsten 2020 oppmeldt 483 studenter som skulle gjennomføre denne oppgaven. Studentene ble delt in 70 grupper ved hjelp av (First Year Study Enviroment -prosjektet (FYSE). FYSE er et prosjekt ved Fakultet for teknologi og realfag der formålet er å bedre nye studenters trivsels- og læringsmiljø på campus. Hver gruppe fikk tildelt en veileder som studentene var ansvarlige for å ta kontakt med. Til sammen deltok 20 faglig ansatte som veiledere for prosjektgruppene. Veilederne hadde ansvaret for å veilede gruppene og å vurdere oppgaven studentene leverte. Vurderingen i prosjektet var bestått/ikke bestått.

I evalueringen kommenterte veilederne at prosjektet er et positivt bidrag til matematikkfaget. Faglærerene hadde vært aktive med i designet av prosjektoppgaven og de opplevde at prosjektoppgaven passet fint inn i fremdriftsplanen for faget.

Studentene skulle levere en skriftlig rapport der de kommuniserer matematikk skriftlig. Veiledere opplever at studentene ikke er vant til å skrive slike prosjektrapporter og at skriftlig matematisk argumentasjon er vanskelig. I ensamensbesvarelsene for faget ser vi også at studenter har problem med å skrive 


\section{Oppgave 2: Vinkler i en leddet mekanisk arm}

En typisk landbasert oljepumpe (derrick) er vist i figuren under. Vi ønsker å beregne vinkelen $\theta_{2}$ i situasjoner der vi kjenner vinkelen $\theta_{1}$. Vi ønsker å tilnærme svaret ved hjelp av NewtonRaphsons metode.

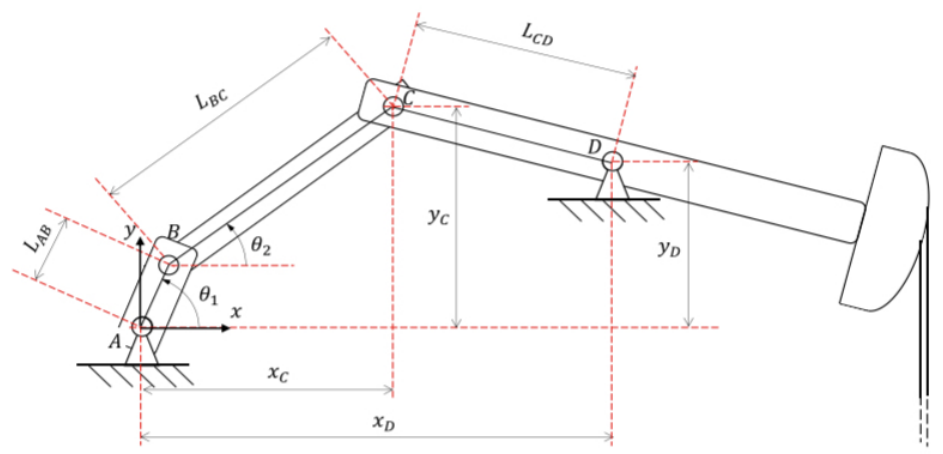

Derricken har følgende dimensjoner: $L_{A B}=2 \mathrm{~m}, L_{B C}=8.5 \mathrm{~m}, L_{C D}=7 \mathrm{~m}, x_{D}=10 \mathrm{~m}$, og $y_{D}=6 \mathrm{~m}$. Videre er følgende relasjoner gyldige:

$$
\left(x_{D}-x_{C}\right)^{2}+\left(y_{D}-y_{C}\right)^{2}=L_{C D}^{2}
$$

der

$$
x_{C}=L_{A B} \cdot c_{1}+L_{B C} \cdot c_{2} \quad \text { og } \quad y_{C}=L_{A B} \cdot s_{1}+L_{B C} \cdot s_{2} .
$$

Her er $c_{i}=\cos \left(\theta_{i}\right)$ og $s_{i}=\sin \left(\theta_{i}\right)$, for $i=1,2$.

Bruk (7) og (8) til å utlede én ligning som vi kan løse for å finne den ukjente $\theta_{2}$ :

$$
f\left(\theta_{2}\right)=0 .
$$

For en gitt $\theta_{1}$ vil denne ligningen har to løsninger. Bruk Newton-Raphsons metode med en feiltoleranse på $E=10^{-12}$ til å finne tilnærminger til begge løsningene i alle tre tilfellene under.

(a) $\operatorname{Løs} f\left(\theta_{2}\right)=0$, når $\theta_{1}=0$.

(b) Løs $f\left(\theta_{2}\right)=0$, når $\theta_{1}=\frac{\pi}{2}$.

(c) $\operatorname{Løs} f\left(\theta_{2}\right)=0$, når $\theta_{1}=\pi$.

Utforsk den fysiske betydningen av de to løsningene i hvert tilfelle.

Finn også sammenhengen mellom initialverdien brukt i løsningsmetoden, og hvilken av de to løsningene metoden konvergerer mot.

Figure 1: Del 2 av prosjektoppgaven 
fullstendige setninger med matematisk innhold. Kommunikasjonskompetanse er en av de matematiske kompetansene vi øsnker å lære studentene med prosjektet. Det ble foreslått at studentene kunne få bedre opplæring i å skrive matematikk ved f. eks ha $\mathrm{LT}_{\mathrm{E}} \mathrm{X}$ - kurs for alle studenter.

Studentene har en variert erfaring med programmering. Noen studenter er godt trent i programmering, mens for andre studenter er dette helt nytt. Selv om prosjektoppgaven ikke krevde mer enn en enkel løkke for å løse oppgavene, føltes dette tungt for de studentene som ikke hadde programmert før. Alle studentene bør få en enkel innføring i programmering før de starter på oppgaven. Dette kan f.eks være innspilte videoforelesninger som forklarer installering, grunnleggende programmering og plotting. Vårt ønske med prosjektoppgaven var at programmering ikke skulle ta mye fokus, men at det ble naturlig å bruke når en skal gjennomføre en iterativ prosess slik Newton Raphsons metode er.

Den største utfordringen veilederne rapporterte om var knyttet til gruppedynamikk. Vi hadde 483 studenter fordelt på 70 grupper. I FYSE-prosjektet er alle studentene delt $\mathrm{i}$ grupper med en eldre student som coach. Denne coachen kontakter studentene og arrangerer møter for studentene. Det er frivillig å delta på FYSE-møter. Vi opplevde at flere studenter ikke deltok aktivt hverken på FYSE-møter eller i prosjektet. Dette førte igjen til konflikter på gruppene som vi ikke var forberedt på. Studentenes ambisjonsnivå og ønske om bidra varierer. Vi observerte derfor at flinke og ambisiøse studenter tok mye ansvar og bidro vesentlig mer enn andre studenter i prosjektet. Flere studenter fremsto som gratispassasjerer. Disse utfordringene bør det jobbes med neste gang en gjennomfører prosjekt i et så stort fag.

MA 178 er delt i to grupper. Den ene gruppen er studenter som starter på universitetet med full fordypingen i matematikk fra videregående. Den andre gruppen kommer inn uten å ha fordypning i matematikk (Y-vei/TRES). Disse studentene må ta et ekstra fag i matematikk den første høsten og har derfor en økt studiebelastning. Den økte studiebelastningen og mindre matematisk bakgrunn for denne gruppen, gjør at flere av disse opplever prosjektoppgaven som vanskelig.

I prosjektet skulle studentene finne ligningen $f\left(\theta_{2}\right)=0$ og siden løse denne. Det var en stor utfordring for studentene å finne uttrykket $f\left(\theta_{2}\right)=0$.Dette løses ved å trekke fra $L_{C D}^{2}$-leddet på begge sider i ligning (7) og sette inn for konstantene. Ligningen $f\left(\theta_{2}\right)=0$ har to løsninger. Studentene skulle drøfte den fysiske betydningen av disse to løsningene. For å forklare dette for studentene brukte flere veiledere en fysisk modell av derricken. Figur 2 viser denne modellen og de to løsningene når $\theta_{1}=\pi / 2$. I figuren til venstre ser vi at albuen peker oppover, mens i figuren til høyre peker albuen nedover. Ved å bruke en fysisk modell var det mye enklere for studentene å koble matematikken til det fysiske problemet.

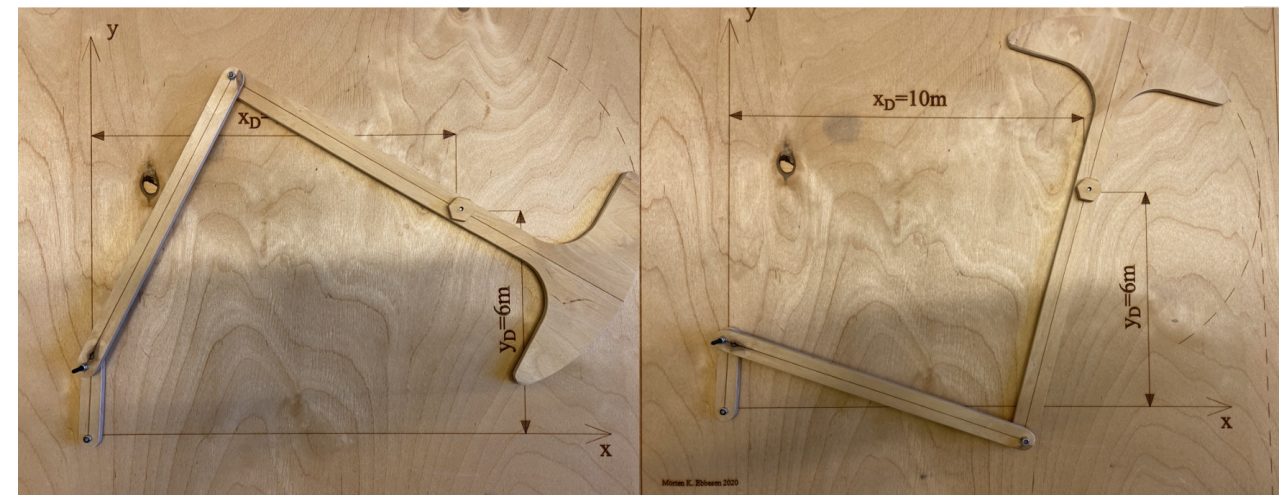

Figure 2: Fysisk modell av derricken (Laget av Morten Kjeld Ebbesen)

Prosjektarbeid er tidkrevende både for studenter og veiledere. Veilederne rapporterte en gjennomsnittlig bruk på 5-6 timer per gruppe til veiledning og evaluering. Med til sammen 70 grupper blir dette 350-400 timer. Hvor mye vi får igjen i økt læringsutbytte for denne økte ressursen i faget er et spørsmål vi må jobbe videre med. 


\section{KONKLUSJON}

Prosjektoppgaven passer fint inn i pensum til faget. Veilederne rapporterer at prosjektoppgaven er et positivt bidrag. Gruppedynamikk er en utfordring som det må jobbes videre med. Totalt har faglig ansatte brukt 350-400 timer på dette prosjektet. Vi har i dette studiet ikke undersøkt studentenes erfaringer eller om dette prosjektet fører til økt læringsutbytte bland studentene.

\section{TAKK}

Takk til alle veiledere i prosjektet: Jan Henriksen, Andreas Otter Wæhle, Rein Terje Thorstensen, Joao Leal, Paul Ragnar Svennevig, Morten Hallquist Rudolfsen, Morten Kjeld Ebbesen, Dag Arvid Kvaavik, Souman Rudra, Folke Haugland, Morgan Konnestad, Zhiyu Jiang, Tom Viggo Nilsen, Michael Rygaard Hansen, Geir Grasmo, Dmitry Vysochinskiy, Mohammad Poursina, Morten Ottestad, Arne Wiklund. Stor takk til Leif Arne Løhaugen og FYSE for hjelp med gruppeinndeling.

\section{REFERANSER}

[1] J. Weintraub, "The Karate Kid". 1984.

[2] M. Savage and M. Grove, "'mathematical modelling and problem solving in real-world physical situations"," in Transitions in Undergraduate Mathematics Education, M. Grove, T. Croft, J. Kyle, and. D. Lawson, Eds., Oxford: Lulu Press, 2015, pp. 115-127.

[3] M. Niss and T. Højgaard, Kompetencer og matematiklaering: Ideer og inspiration til udvikling af matematikundervisning i Danmark. Jan. 2002, ISBN: 8760322446.

[4] B. Jaworski, "What does it mean to learn mathematics?" Foredrag for Ingeniørstudenter UiA 20. September 2018, 2018.

[5] K. Singh, Engineering mathematics through applications, eng, 2nd ed.. Palgrave Macmillan, 2011, ISBN: 9780230274792.

[6] Y. F. Zakariya, H. K. Nilsen, S. Goodchild, and K. Bjørkestøl, "Self-efficacy and approaches to learning mathematics among engineering students: Empirical evidence for potential causal relations," International Journal of Mathematical Education in Science and Technology, vol. 0, no. 0, pp. 1-15, 2020. DOI: 10.1080/0020739X . 2020.1783006. 